\title{
$\beta$ Common Receptor Mediates Erythropoietin-Conferred Protection on OxLDL-Induced Lipid Accumulation and Inflammation in Macrophages
}

\author{
Tzong-Shyuan Lee, ${ }^{1,2,3}$ Kuo-Yun Lu, ${ }^{1}$ Yuan-Bin Yu, \\ Hsueh-Te Lee, ${ }^{2,5}$ and Feng-Chuan Tsai ${ }^{5}$ \\ ${ }^{1}$ Department of Physiology, National Yang-Ming University, Taipei 11221, Taiwan \\ ${ }^{2}$ Brain Research Center, National Yang-Ming University, Taipei 11221, Taiwan \\ ${ }^{3}$ Genome Research Center, National Yang-Ming University, Taipei 11221, Taiwan \\ ${ }^{4}$ Division of Hematology and Oncology, Taipei Veterans General Hospital, Taipei 11221, Taiwan \\ ${ }^{5}$ Institute of Anatomy and Cell Biology, National Yang-Ming University, Taipei 11221, Taiwan
}

Correspondence should be addressed to Tzong-Shyuan Lee; tslee@ym.edu.tw

Received 10 September 2014; Accepted 31 December 2014

Academic Editor: Ishak O. Tekin

Copyright (C) 2015 Tzong-Shyuan Lee et al. This is an open access article distributed under the Creative Commons Attribution License, which permits unrestricted use, distribution, and reproduction in any medium, provided the original work is properly cited.

Erythropoietin (EPO), the key factor for erythropoiesis, also protects macrophage foam cells from lipid accumulation, yet the definitive mechanisms are not fully understood. $\beta$ common receptor $(\beta C R)$ plays a crucial role in the nonhematopoietic effects of EPO. In the current study, we investigated the role of $\beta \mathrm{CR}$ in EPO-mediated protection in macrophages against oxidized low-density lipoprotein- (oxLDL-) induced deregulation of lipid metabolism and inflammation. Here, we show that $\beta C R$ expression was mainly in foamy macrophages of atherosclerotic aortas from apolipoprotein E-deficient mice. Results of confocal microscopy and immunoprecipitation analyses revealed that $\beta \mathrm{CR}$ was colocalized and interacted with EPO receptor (EPOR) in macrophages. Inhibition of $\beta \mathrm{CR}$ activation by neutralizing antibody or small interfering RNA (siRNA) abolished the EPOconferred protection in oxLDL-induced lipid accumulation. Furthermore, EPO-promoted cholesterol efflux and upregulation of ATP-binding cassette $(\mathrm{ABC})$ transporters $\mathrm{ABCA1}$ and $\mathrm{ABCG1}$ were prevented by pretreatment with $\beta C R$ neutralizing antibody or $\beta C R$ siRNA. Additionally, blockage of $\beta C R$ abrogated the EPO-conferred anti-inflammatory action on oxLDL-induced production of macrophage inflammatory protein-2. Collectively, our findings suggest that $\beta \mathrm{CR}$ may play an important role in the beneficial effects of EPO against oxLDL-elicited dysfunction of macrophage foam cells.

\section{Introduction}

Erythropoietin (EPO) was first identified in kidney to function as a crucial humoral regulator in erythropoiesis by promoting proliferation, differentiation, and survival of erythroid precursors $[1,2]$. Based on this biological activity, EPO has been used for the treatment of selected red blood disorders in patients $[2,3]$. Now, it is evident that EPO and its receptor, EPOR, exhibit a widespread distribution among a variety of organs in addition to kidney $[1,3,4]$. Recently, a large body of additional studies demonstrates that EPO also has several extrahematopoietic protective effects on the cardiovascular system, nervous system, and immunity [48]. For instance, EPO enhances reendothelialization after vascular injury and protects the endothelial cells (ECs) from hypoxia-induced apoptosis $[7,9,10]$. EPO promotes neuron development, prevents cell death of neurons, and improves learning and memory [11-13]. Furthermore, EPO retards the progression of atherosclerosis in chronic kidney disease patients [12]. We previously reported that EPO inhibits the formation of macrophage foam cells by promoting the efficacy of cholesterol efflux [13]. Emerging evidence suggests that $\beta$ common receptor $(\beta \mathrm{CR})$, a shared receptor subunit of interleukin-3 (IL-3), IL-5, and granulocyte-macrophage colony stimulation factor (GM-CSF) receptors, mediates several nonhematopoietic effects of EPO in various types of cells [14-18]. Blockage of $\beta C R$ activity by neutralizing antibody prevents the EPO-mediated endothelial nitric oxide synthase 
(eNOS) activation and nitric oxide (NO) production in ECs [17]. Genetic deletion of $\beta$ CR abrogates the protective effect of EPO in spinal cord injury mouse model [18]. Although the implication of EPO in deregulation of cholesterol metabolism of foam cells has been defined, the role of $\beta C R$ in pathophysiology of macrophage foam cells is poorly understood. To this end, further investigation delineating the role of $\beta \mathrm{CR}$ in EPOmediated benefits in the lipid metabolism and inflammation of foam cells is warranted.

Complications of atherosclerosis are the leading cause of death in developed and developing countries. Deregulation of cholesterol metabolism is the most critical factor for the development of atherosclerosis, which leads to the deposition of excessive cholesterol within vessel wall and persistent vascular inflammation $[19,20]$. Macrophage foam cell-mediated regulation of cholesterol metabolism and inflammation are central events in the initiation and progression of atherosclerosis [21-24]. Excessive lipid accumulation inside macrophage foam cells is mainly due to uncontrolled uptake of oxidized low-density lipoprotein (oxLDL) or impaired cholesterol efflux in macrophages [23, 24]. Intracellular lipid contents of macrophage foam cells are tightly regulated by scavenger receptors (SRs) and cholesterol efflux transporters. In macrophage foam cells, SRs such as SR-A and CD36 are responsible for internalizing oxLDL $[25,26]$. In contrast, the efflux of intracellular cholesterol to high-density lipoprotein (HDL) is mediated by cholesterol efflux transporters including SR-BI and ATP-binding cassette (ABC) transporters [2729]. Emerging evidence suggests that lowers lipid accumulation and inflammation by upregulating $\mathrm{ABC}$ transporters can be a therapeutic strategy for treating or preventing atherosclerosis [30-35]. Our previous study shows EPO upregulates the expression of ABCA1 and ABCG1 without affecting expression of SR-BI, SR-A, and CD36 in macrophages [13]. However, how $\beta \mathrm{CR}$ involves in EPO-elicited reduction in oxLDL-induced lipid accumulation and inflammation of macrophage foam cells remains to be explored.

Given the importance of $\beta C R$ in EPO-conferred nonhematopoietic protection, in the present study, we aimed to investigate the role of $\beta \mathrm{CR}$ in $\mathrm{EPO}$-conferred protection from the formation of macrophage foam cells in bonemarrow-derived macrophages (BMDMs). This study was conducted, firstly, to investigate the protein expression of $\beta \mathrm{CR}$ in atherosclerotic aortas and macrophages; secondly, to delineate the role of $\beta C R$ in the suppression of EPO on cholesterol accumulation; and thirdly, to explore the role of $\beta \mathrm{CR}$ in oxLDL-elicited inflammation in macrophages. We found that the inhibition of $\beta \mathrm{CR}$ abolished the EPO-conferred protection from oxLDL-induced deregulation of lipid metabolism and inflammatory response in macrophages.

\section{Materials and Methods}

2.1. Reagents. Recombinant mouse erythropoietin (rhEPO), macrophage colony stimulating factor (M-CSF), and macrophage inflammatory protein-2 (MIP-2) ELISA kits were obtained from R\&D Systems (Minneapolis, MN, USA). Minimum essential medium $\alpha(\mathrm{MEM} \alpha)$ and RPMI 1640 medium were purchased from Gibco Life Technology (Karlsruhe, Germany). Goat anti-EPO, rabbit anti-EPOR, anti- $\beta C R$ antibodies, control small interfering RNA (siRNA), and $\beta C R$ siRNA were obtained from Santa Cruz Biotechnology (Santa Cruz, CA, USA). Mouse anti-ABCA1 antibody was obtained from Abcam (Cambridge, MA, USA). Rabbit anti-ABCG1 was from Novus Biologicals (Littleton, CO, USA). Mouse anti$\alpha$-tubulin antibody, apolipoprotein AI (apoAI), high-density lipoprotein (HDL), 3,3-diaminobenzidine (DAB), bovine serum albumin (BSA), and human LDL were purchased from Sigma Chemical (St. Louis, MO, USA). NBD-cholesterol was from Cayman Chemical (Ann Arbor, MI, USA). Cholesterol and triglyceride assay kits were from Randox (Crumlin Co., Antrim, UK).

2.2. Immunohistochemical Assessment. Formalin-fixed, paraffin-embedded tissue blocks were cut into $8 \mu \mathrm{M}$ sections. Samples were mounted on positively charged glass microscope slides. Sections were deparaffinized, rehydrated, and then covered $3 \% \mathrm{H}_{2} \mathrm{O}_{2}$ for $10 \mathrm{~min}$. After incubation with blocking BSA for $30 \mathrm{~min}$, slides were incubated with one of the following primary antibodies for $1 \mathrm{~h}$ at $37^{\circ} \mathrm{C}$ : EPOR or $\beta C R$. Then, sections were incubated with second antibodies appropriate for primary antibodies for $1 \mathrm{~h}$ at $37^{\circ} \mathrm{C}$. Antigenic sites were visualized by the addition of DAB. Slides were counterstained with hematoxylin. Negative control slides were stained using the same procedure, omitting the primary antibody.

2.3. Cell Culture. Bone-marrow-derived macrophages (BMDMs) were prepared as previously described [36]. Briefly, SJL mice were killed by carbon dioxide exposure. Mononuclear cells were obtained from the femurs and tibias and were harvested by Percoll $\left(1.073 \mathrm{~g} / \mathrm{cm}^{3}\right)$ density gradient centrifugation. The cells were then seeded in MEM $\alpha$ supplemented with $50 \mathrm{ng} / \mathrm{mL}$ M-CSF, $10 \% \mathrm{FBS}$, and penicillin $(100 \mathrm{U} / \mathrm{mL}) /$ streptomycin $(100 \mu \mathrm{g} / \mathrm{mL})$ at $37^{\circ} \mathrm{C}$ in humidified air with $5 \% \mathrm{CO}_{2}$ for 5 days until cell populations became $80 \%$ confluent. All animal experiments were approved by the Animal Care and Utilization Committee of the National Yang-Ming University, Taiwan.

2.4. Low-Density Lipoprotein Modification. The oxLDL was prepared as described previously [37]. Briefly, LDL was exposed to $5 \mu \mathrm{M} \mathrm{CuSO}$ for $24 \mathrm{~h}$ at $37^{\circ} \mathrm{C}$ and $\mathrm{Cu}^{2+}$ was then removed by extensive dialysis. The extent of modification was determined by the measurement of thiobarbituric acid-reactive substances (TBARs). The oxLDL containing approximately 30-60 nmol of TBARs as malondialdehyde equivalents per milligrams of LDL protein was used for experiments.

2.5. Oil-Red O Staining. After fixation in $4 \%$ paraformaldehyde, cells were stained by oil-red $\mathrm{O}$ staining for $30 \mathrm{~min}$. Hematoxylin was used as counterstaining. The density of lipid content was evaluated by alcohol extraction after oil-red $\mathrm{O}$ staining. 
2.6. Cholesterol and Triglyceride Measurement. Cellular cholesterol and triglycerides were extracted by the use of hexane/isopropanol $(3 / 2, \mathrm{v} / \mathrm{v})$. After expelling cellular debris, the supernatant was dried under nitrogen flush. Cholesterol and triglycerides content were measured by the use of cholesterol and triglyceride assay kits.

2.7. Quantitative Real-Time RT-PCR. Total cellular RNA was extracted by the use of total RNA reagent. A $5 \mu \mathrm{g}$ amount of total RNA was converted to complementary DNA (cDNA) by the use of reverse transcriptase (Fermentas, MD, USA). The resulting CDNA was used as templates for quantitative realtime RT-PCR (qPCR) with the TaqMan probe-based realtime quantification system (Applied Biosystems, Foster, CA, USA). The mRNA levels were normalized to those of GAPDH and expressed as fold change over controls.

2.8. Western Blot. Cells were rinsed twice with ice-cold PBS and then lysed with PBS containing $1 \%$ Triton X-100, $0.1 \%$ SDS, $0.5 \%$ sodium deoxycholate, $1 \mu \mathrm{g} / \mathrm{mL}$ leupeptin, $10 \mu \mathrm{g} /$ $\mathrm{mL}$ aprotinin, and $1 \mathrm{mM}$ phenylmethylsulfonyl fluoride on ice. After sonication for $15 \mathrm{~s}$, crude extracts were subjected to centrifugation at $12000 \times \mathrm{g}$ for $5 \mathrm{~min}$ at $4^{\circ} \mathrm{C}$. The supernatants were collected as cell lysates. All protein concentrations were determined by a protein assay (Bio-Rad Laboratories, Richmond, CA, USA). Aliquots $(50 \mu \mathrm{g})$ of cell lysates or nuclear extracts were separated and electrophoresed on 8 or $12 \%$ SDS-polyacrylamide gel and then transblotted onto the Immobilon-P membrane (Millipore, Bedford, MA, USA). After being blocked with 5\% skim milk in Tween/PBS, blots were incubated with various primary antibodies and then incubated with HRP-conjugated secondary antibodies. The protein bands in the blots were detected using enhanced chemiluminescence kit and quantified by ImageQuant 5.2 software (Healthcare Bio-Sciences, Philadelphia, PA, USA).

2.9. Statistical Analysis. Results are presented as mean \pm SEM from 5 independent experiments. Mann-Whitney test was used to compare 2 independent groups. Kruskal-Wallis followed by the Bonferroni post hoc analysis was used to account for multiple testing. Statistical analysis involved SPSS v18.0 (SPSS Inc., Chicago, IL, USA). A $P<0.05$ was considered statistically significant.

\section{Results}

3.1. $\beta C R$ Is Expressed in Atherosclerotic Lesions and Macrophages. To study the possible role of $\beta \mathrm{CR}$ in atherogenesis, we first investigated the expression of $\beta \mathrm{CR}$ in atherosclerotic lesions. Immunohistochemical staining for $\beta \mathrm{CR}$ demonstrated that $\beta$ CR was colocalized with EPOR and its positive signals are restricted mainly to areas of macrophages in atherosclerotic lesions of apoE $\mathrm{E}^{-/-}$mice (Figure 1). Results of confocal microscopy further confirm that $\beta$ CR was detectable in BMDMs (Figure 2). These results imply that $\beta C R$ may play a role in the biology of macrophage foam cells and atherogenesis.
3.2. EPO Does Not Affect the Dimerization of $\beta C R$ and EPOR in Macrophages. It has been demonstrated that $\beta \mathrm{CR} / \mathrm{EPOR}$ dimer is crucial for the nonhematopoietic protective effects of EPO [14-18]. We therefore examined whether EPO could alter the status of $\beta \mathrm{CR} / \mathrm{EPOR}$ dimerization in macrophages. We found that treatment with EPO had no effect on the dimerization of $\beta$ CR and EPOR (Figure 3).

3.3. $\beta C R$ Mediates the EPO-Conferred Protection from Foam Cell Formation. We have reported the beneficial effect of EPO on oxLDL-induced the lipid accumulation in macrophages [13]. We then determined the functional significance of $\beta C R$ in EPO-mediated protection from foam cell formation in BMDMs. Loss of function of $\beta C R$ by neutralizing $A b$ or knockdown gene expression demonstrated that EPO failed to prevent the foam cell formation in BMDMs as compared to the IgG- or control siRNA-treated BMDMs (Figures 4 and 5). These findings suggest that $\beta \mathrm{CR}$ plays a crucial role in the EPO-conferred protection in the formation of macrophage foam cells.

3.4. $\beta C R$ Is Essential for the EPO-Elicited Promotion of Cholesterol Efflux in Macrophages. EPO is known to promote the ABC transporter-dependent cholesterol efflux in macrophages [13]. We then investigated the role of $\beta C R$ in EPO-mediated increase in cholesterol efflux and expression of ABCA1 and ABCG1. Our data showed that treatment with $\beta C R$ neutralizing $\mathrm{Ab}$ or $\beta \mathrm{CR}$ siRNA abolished EPOstimulated apoAI- and HDL-dependent cholesterol efflux in BMDMs (Figure 6). In addition, the mRNA and protein expression of ABCA1 and ABCG1 induced by EPO were prevented under the condition with the loss of function of $\beta \mathrm{CR}$ (Figure 7). Collectively, these data suggest that the $\beta \mathrm{CR}$ is required for the EPO-induced suppression of intracellular lipid accumulation in macrophage foam cells.

3.5. $\beta C R$ Is a Key Molecule for the Anti-Inflammatory Effect of EPO in OxLDL-Induced Inflammation. EPO is reported to have anti-inflammatory properties [38, 39]. We next examined the role of $\beta C R$ in oxLDL-induced production of MIP-2 in BMDMs. Our data showed that MIP-2 production increased in a concentration-dependent manner with oxLDL treatment (Figure 8(a)). This oxLDL-increased production of MIP-2 in BMDMs was significantly attenuated by treatment with the EPO (Figure 8(b)). Moreover, pretreatment with $\beta C R$ neutralizing $\mathrm{Ab}$ or $\beta \mathrm{CR}$ siRNA abolished EPO-provided anti-inflammatory effect on oxLDL-induced MIP-2 production (Figures $8(\mathrm{c})$ and $8(\mathrm{~d})$ ). These results suggest that $\beta C R$ may be required for the anti-inflammatory action of EPO in the process of macrophage foam cell formation in response to oxLDL challenge.

\section{Discussion}

EPO, the key hormone for erythropoiesis, also has inhibitory effect on the formation of macrophage foam cells, yet the 

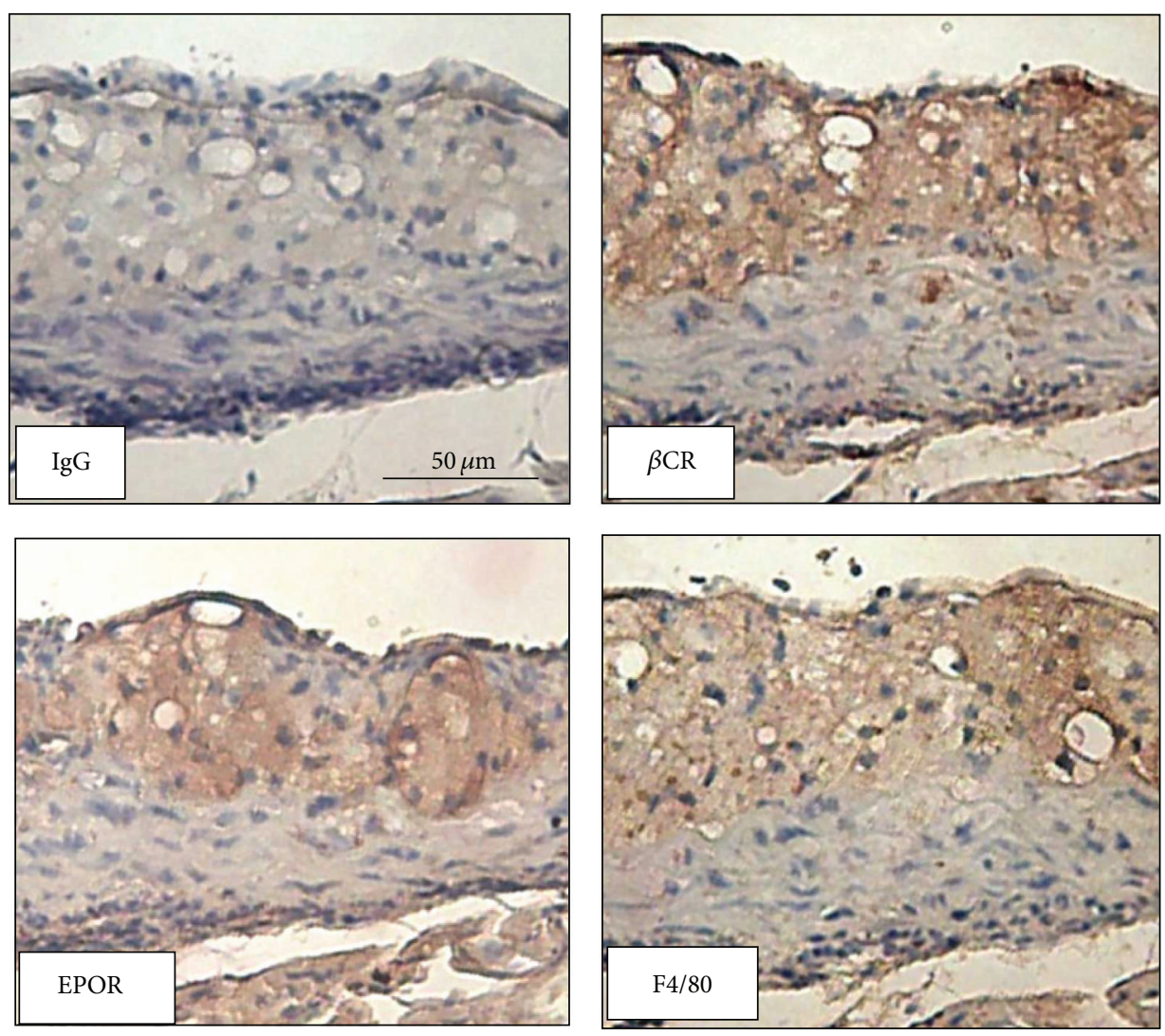

FIGURE 1: Expression of $\beta C R$ in atherosclerotic lesions of apoE ${ }^{-/-}$mice. Immunohistochemistry with IgG, anti- $\beta \mathrm{CR}$, anti-EPOR, or antiF4/80 was performed and then recognized by the corresponding horseradish peroxidase-conjugated secondaryantibody on aortic specimens of apoE deficient mice. Hematoxylin was used as counterstaining.
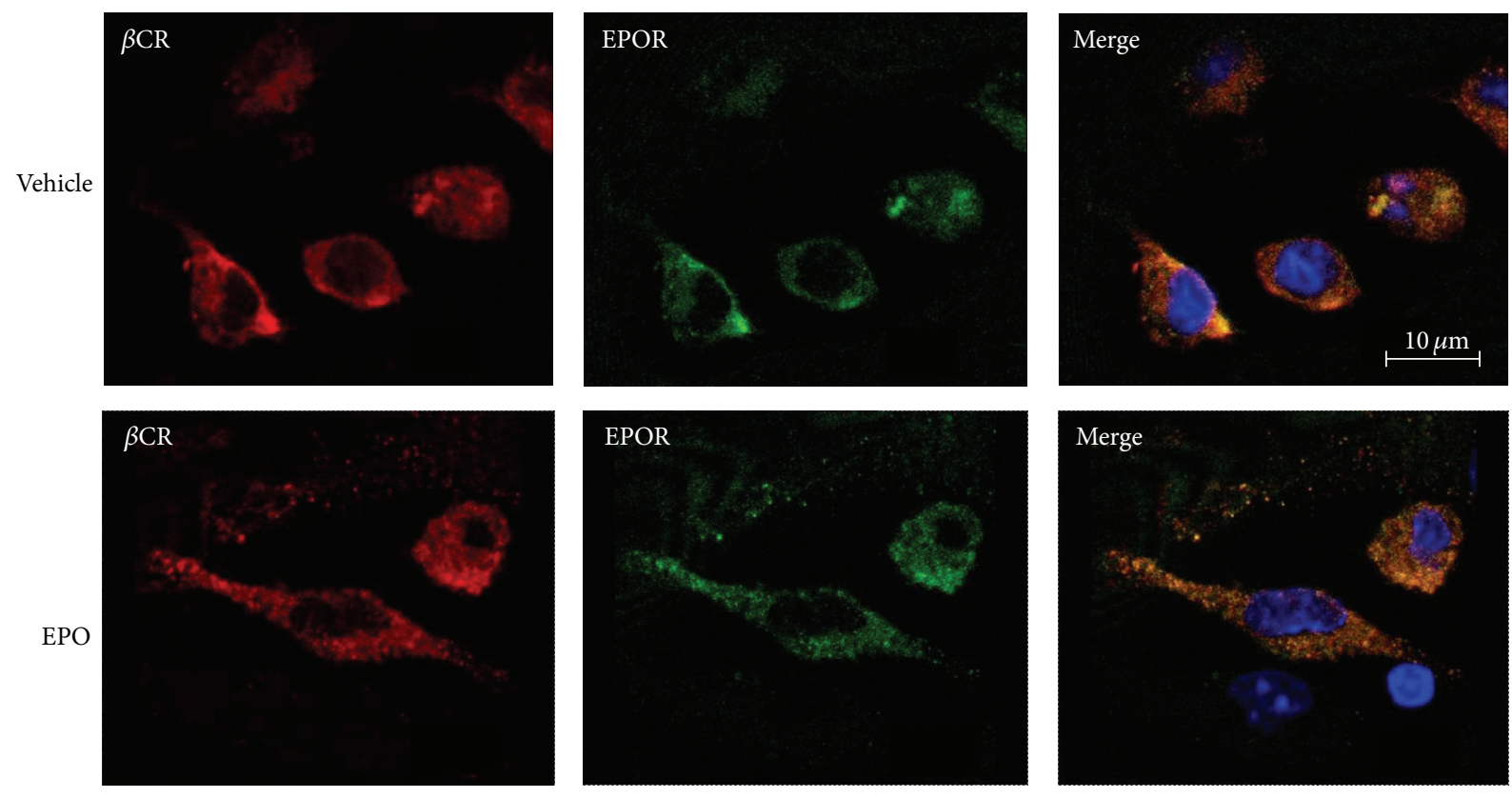

FIGURE 2: $\beta$ CR colocalizes with erythropoietin receptor (EPOR) in macrophagesbone-marrow-derived macrophages were treated with vehicle (PBS) or EPO $(5 \mathrm{U} / \mathrm{mL})$ for $10 \mathrm{~min}$. Cells were fixed and immunostained with anti- $\beta \mathrm{CR}$ or anti-EPOR Ab for confocal microscopy examination. Nuclei were stained with DAPI. 

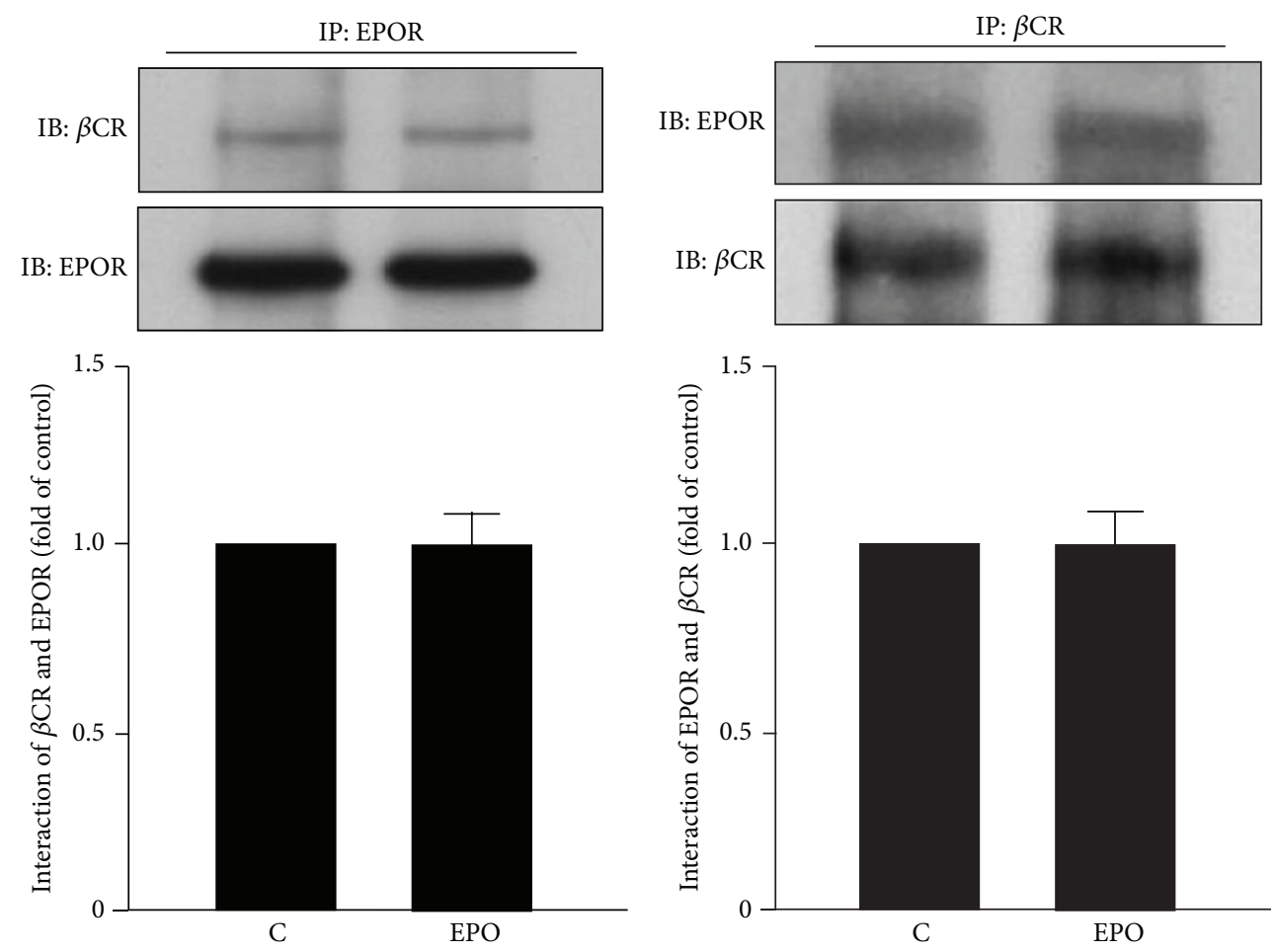

(a)

(b)

FIGURE 3: EPO treatment does not affect the interaction of $\beta$ CR and EPOR in macrophages. Macrophages were treated with or without EPO $(5 \mathrm{U} / \mathrm{mL})$ for $10 \mathrm{~min}$. Cellular lysates were immunoprecipitated (IP) with (a) anti-EPOR Ab or (b) anti- $\beta$ CR Ab and then were immunoprobed with anti-EPOR or anti- $\beta$ CR Ab by immunoblotting (IB). Data are mean \pm SEM from 5 independent experiments.

detailed molecular mechanisms are not fully understood. We investigated the role of $\beta C R$ in EPO-mediated suppression on oxLDL-induced lipid accumulation and inflammation. Our results demonstrated that $\beta \mathrm{CR}$ may play an important role in the EPO-mediated cholesterol metabolism and attenuation in oxLDL-induced inflammation in BMDMs. We first validated that $\beta \mathrm{CR}$ was colocalized and interacted with EPOR in macrophages and in atherosclerotic lesions. Pretreatment with neutralizing antibody or siRNA for $\beta \mathrm{CR}$ abolished the EPO-conferred protection against oxLDL-induced lipid accumulation and abrogated the EPO-induced upregulation of $\mathrm{ABC}$ transporters and the resulting surge of cholesterol efflux. The same treatment towards $\beta C R$ also rendered the EPO anti-inflammatory activity against oxLDL-induced MIP-2 production ineffective. Accordingly, these findings suggest that $\beta$ CR plays a key role in the nonhematopoietic benefits of EPO and may have therapeutic value in the treatment of atherosclerosis and disorders of lipid metabolism.

Emerging evidence indicates the crucial influence of EPO on the regulation of physiological functions of cardiovascular system and the pathogenesis of cardiovascular diseases $[7,8$, 17, 40-43]. Experimental data indicate that EPO maintains the integrity of endothelial cells through an eNOS-dependent mechanism, and deletion of EPO or EPOR leads to angiogenic defects in the vascular system during embryogenesis [7, 8, 17, 40, 41]. Moreover, EPO improves cardiac function by increasing blood flow and inhibiting myocyte apoptosis in ischemia rodent models $[42,43]$. On the contrary, clinical observations demonstrate that the mortality and morbidity rate are elevated in patients with acute ischemia stroke or chronic kidney diseases when administrated with EPO [44, 45]. Yet, there is not sufficient evidence to explain how EPO elicit these unfavorable effects in these EPO-treated patients.

Notably, the profile of lipid or apolipoproteins in hemodialysis patients was changed with long-term treatment with EPO [12, 46, 47]. Moreover, Buemi et al. reported that administration with EPO significantly reduced the cholesterol ester content of atherosclerotic aortas in Watanabe heritable hyperlipidemia rabbits [48]. Although the detailed cellular and molecular mechanisms by which EPO regulates the lipid metabolism in vivo are unclear, our previous findings suggest that EPO can directly regulate the cholesterol metabolism of macrophage foam cells by promoting cholesterol efflux. In this study, we further confirmed this beneficial effect of EPO and provide new evidence regarding with the implication of $\beta C R$ in this antiatherogenic property of EPO.

EPO was first identified as a hormone produced in the kidney that promotes the erythropoiesis in bone marrow [1, $3,4]$. EPO regulates erythropoiesis by binding to the classical, homodimeric complex of two EPO receptors (EPOR2) on erythroid progenitor cells $[3,4]$. Notably, the nonhematopoietic protection of EPO in other types of cells is mediated by the binding of EPO to a heteromeric receptor complex consisting of two EPOR and two $\beta \mathrm{CR}$ (EPOR2- $\beta \mathrm{CR} 2$ ) 


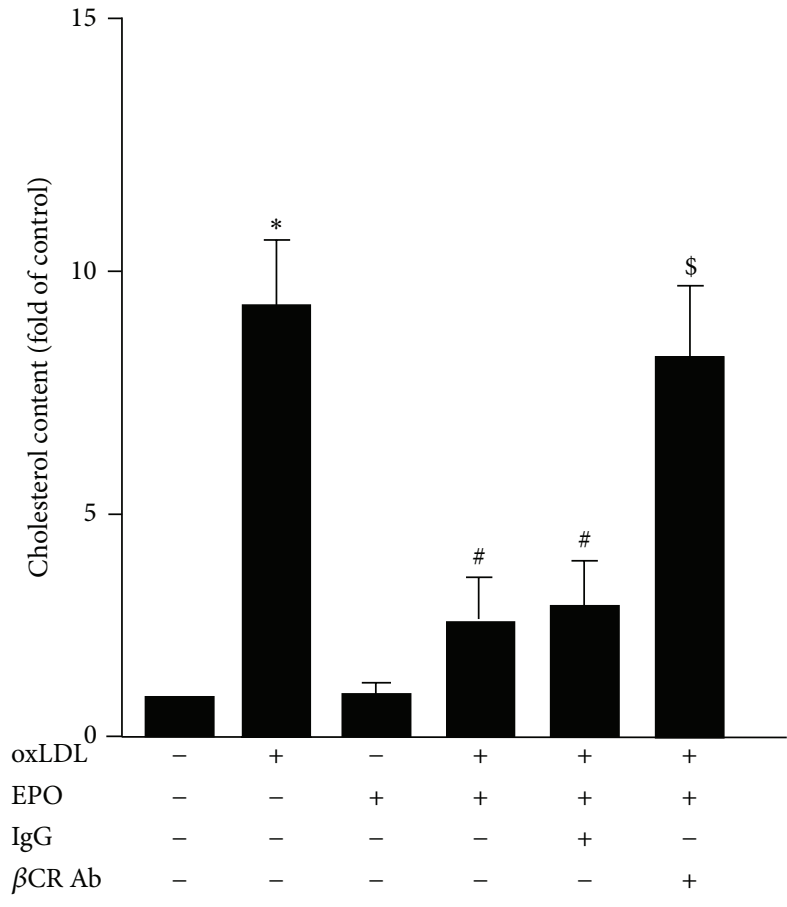

(a)
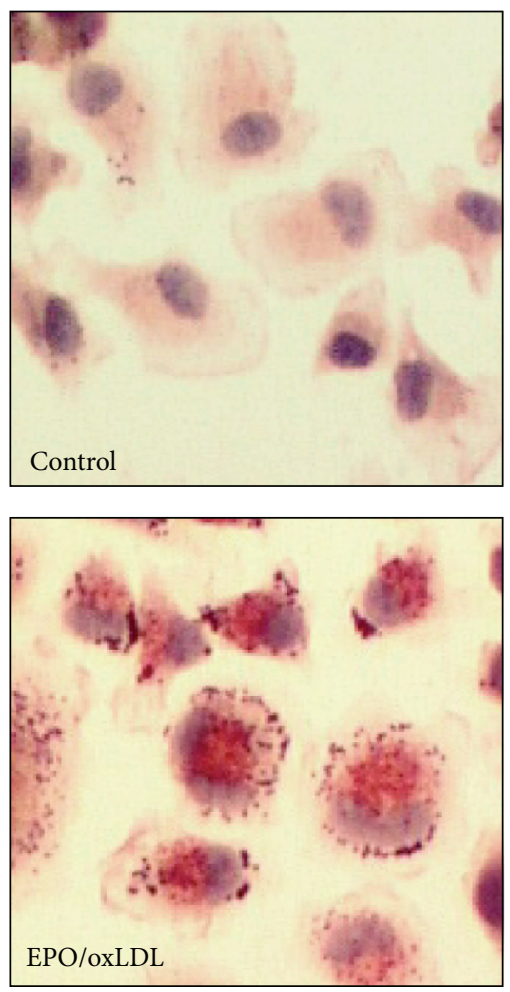
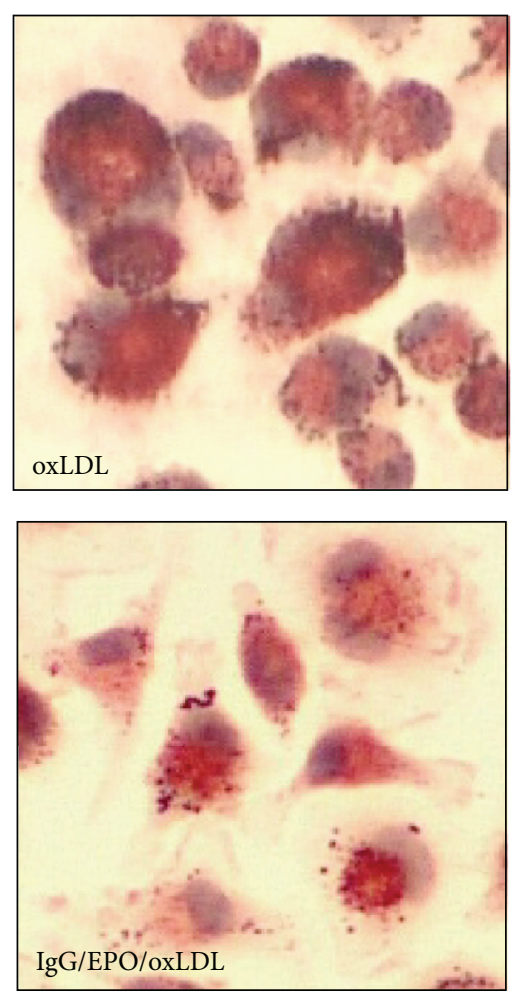

(c)

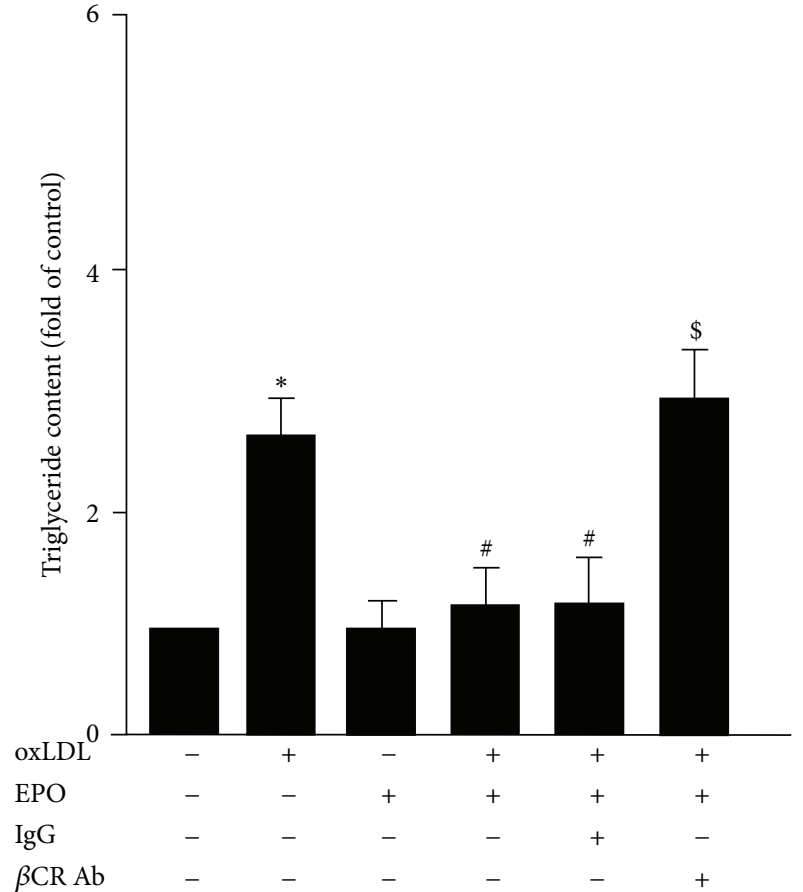

(b)
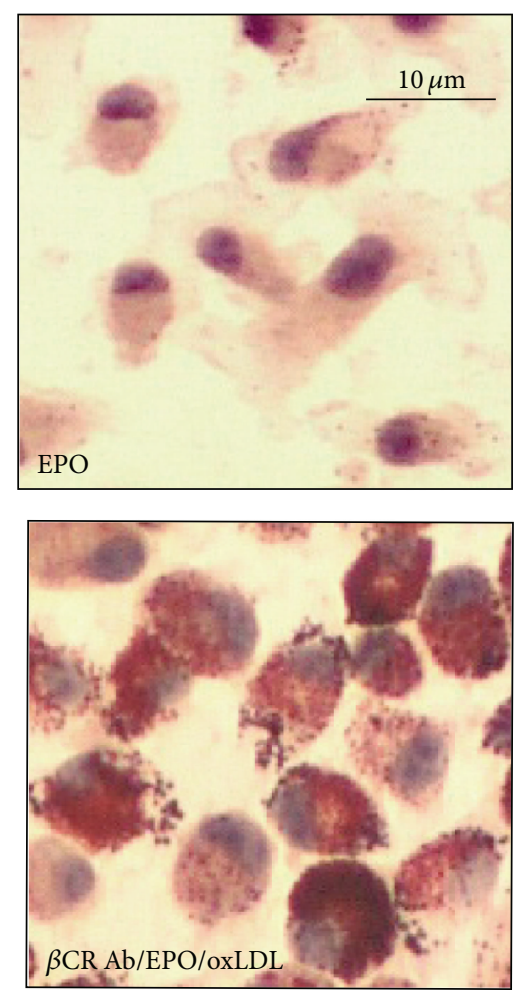

FIgURE 4: $\beta$ CR neutralizing Ab diminishes the EPO-mediated protection of oxLDL-induced lipid accumulation in macrophages. Bonemarrow-derived macrophages were pretreated with $\operatorname{IgG}(200 \mathrm{ng} / \mathrm{mL})$ or $\beta C R$ neutralizing $\mathrm{Ab}(200 \mathrm{ng} / \mathrm{mL})$ for $2 \mathrm{~h}$ and then treated with EPO $(5 \mathrm{U} / \mathrm{mL})$ for $12 \mathrm{~h}$, followed by oxLDL $(50 \mu \mathrm{g} / \mathrm{mL})$ for additional $18 \mathrm{~h}$. ((a) and (b)) The intracellular levels of cholesterol (a) and triglyceride (b) were extracted by hexane/isopropanol $(3 / 2, \mathrm{v} / \mathrm{v})$ and analyzed by colorimetric assay kits or (c) subjected to oil-red $\mathrm{O}$ staining. Cellular nuclei were stained with hematoxylin. Data is mean \pm SEM from 5 independent experiments. ${ }^{*} P<0.05$ versus vehicle-treated group, ${ }^{\#} P<0.05$ versus oxLDL alone-treated group, ${ }^{\$} P<0.05$ versus oxLDL+EPO-treated group. 


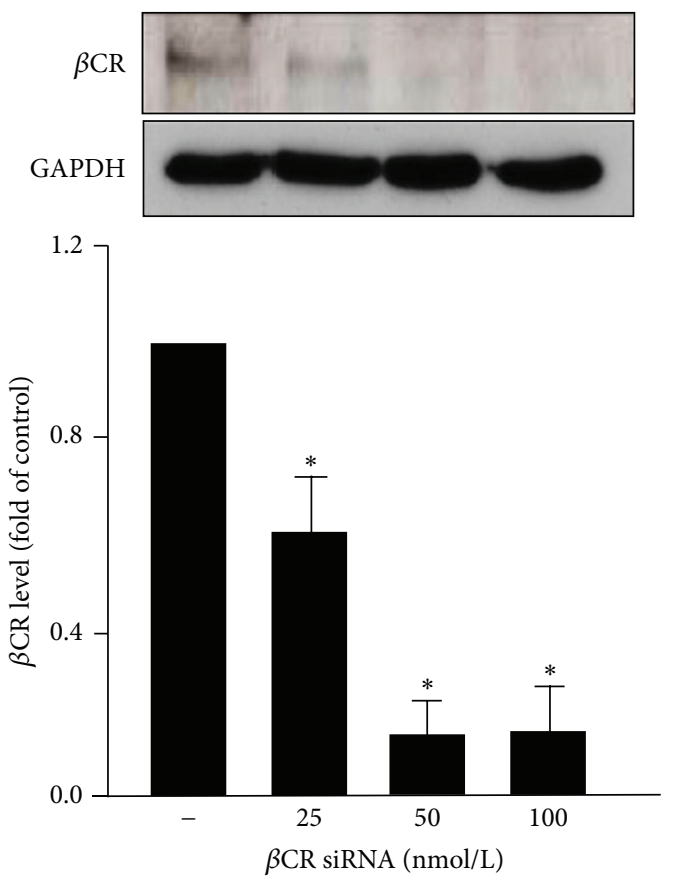

(a)

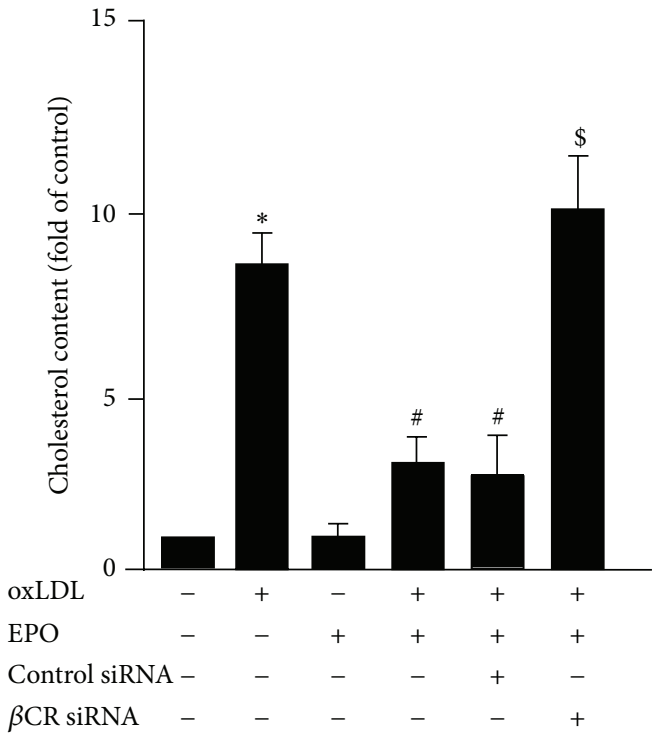

(b)

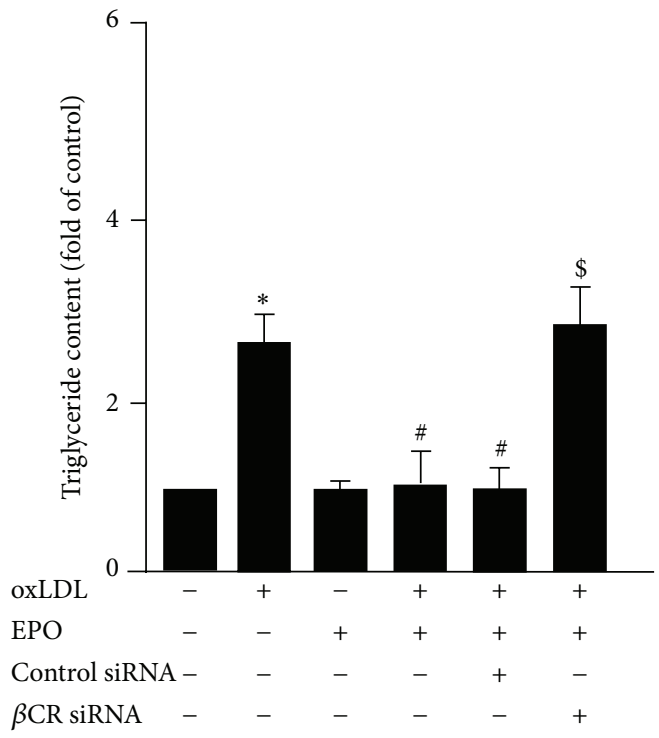

(c)
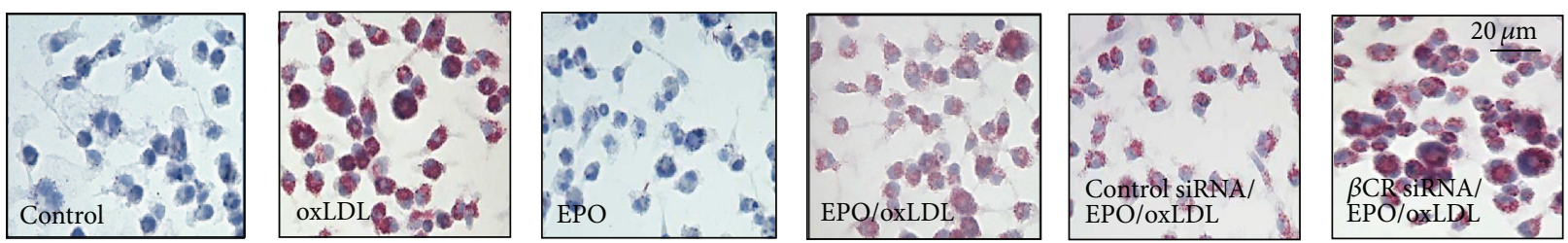

(d)

Figure 5: Knockdown of $\beta$ CR expression ablates the EPO-mediated protection of oxLDL-induced lipid accumulation in macrophages. (a) Bone-marrow-derived macrophages were transfected with indicated concentrations of $\beta \mathrm{CR}$ siRNA $(25,50$, and $100 \mathrm{nmole} / \mathrm{L})$ for $24 \mathrm{~h}$. Protein level of $\beta$ CR was examined by western blot analysis. Cells were transfected with control siRNA ( $50 \mathrm{nmole} / \mathrm{L})$ or $\beta \mathrm{CR}$ siRNA (50 nmole/L) for $24 \mathrm{~h}$ and then treated with EPO $(5 \mathrm{U} / \mathrm{mL})$ for $12 \mathrm{~h}$, followed by oxLDL $(50 \mu \mathrm{g} / \mathrm{mL})$ for additional $18 \mathrm{~h}$. ((b) and (c)) The intracellular levels of cholesterol and triglyceride were extracted by hexane/isopropanol $(3 / 2, \mathrm{v} / \mathrm{v})$ and analyzed by colorimetric assay kits or (d) subjected to oil-red O staining. Cellular nuclei were stained with hematoxylin. Data is mean \pm SEM from 5 independent experiments. ${ }^{*} P<0.05$ versus vehicle-treated group, ${ }^{\#} P<0.05$ versus oxLDL alone-treated group, ${ }^{\$} P<0.05$ versus oxLDL+EPO-treated group. 


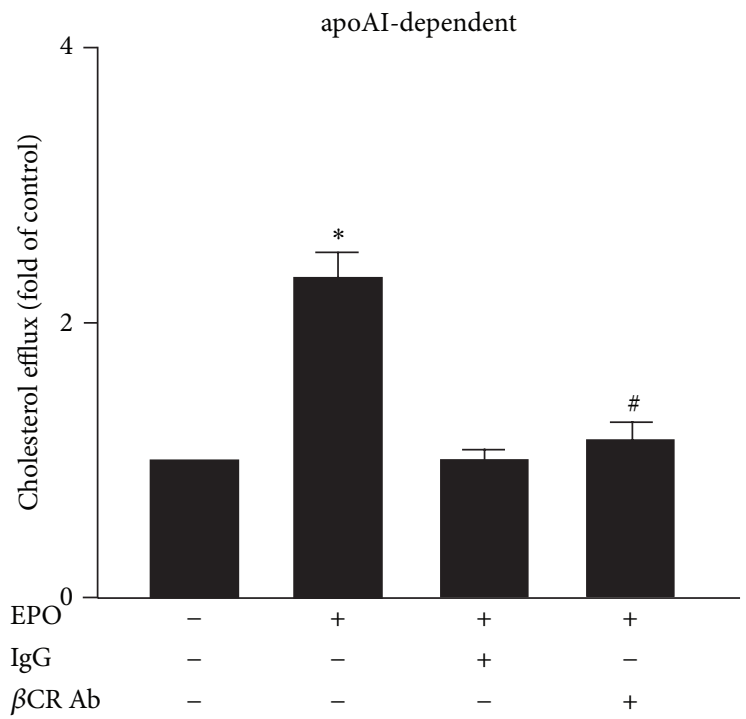

HDL-dependent

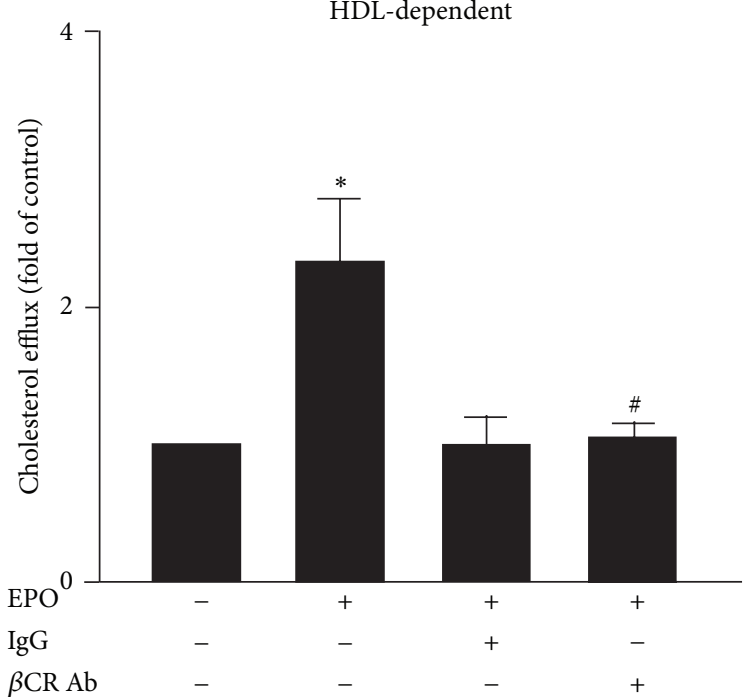

(a)

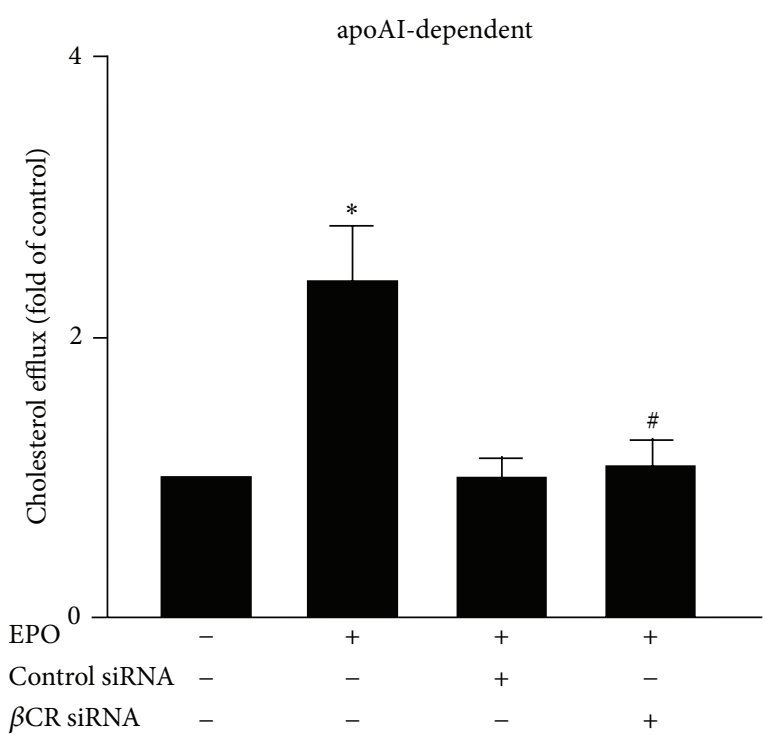

HDL-dependent

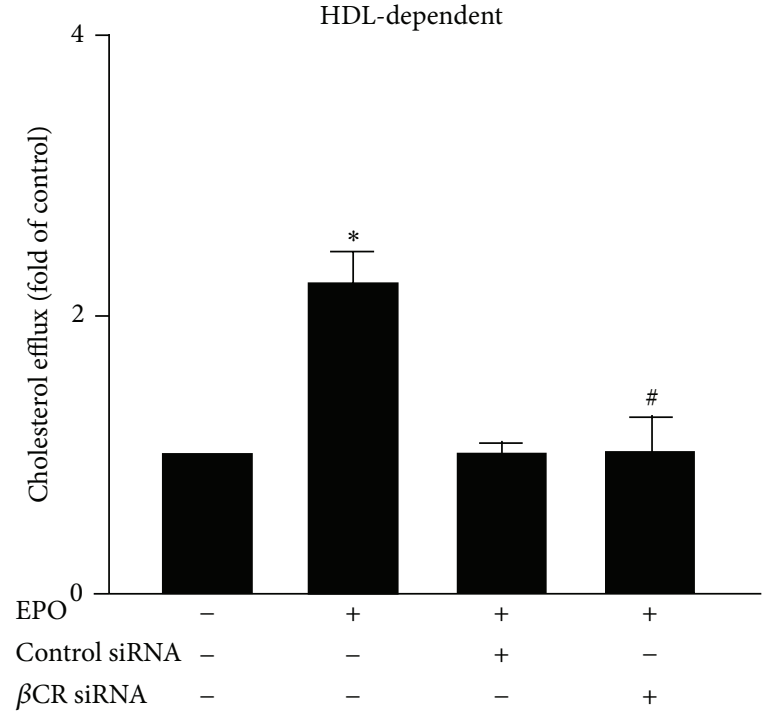

(b)

FIGURE 6: Inhibition of $\beta$ CR activation abolishes the EPO-mediated promotion of cholesterol efflux in macrophages. Bone-marrow-derived macrophages were pretreated with IgG $(200 \mathrm{ng} / \mathrm{mL})$ or $\beta C R$ neutralizing $\mathrm{Ab}(200 \mathrm{ng} / \mathrm{mL})$ for $2 \mathrm{~h}$ (b) transfection with control siRNA $(50 \mathrm{nmole} / \mathrm{L})$ or $\beta$ CR siRNA $(50 \mathrm{nmole} / \mathrm{L})$ for $24 \mathrm{~h}$ and then treated with EPO $(5 \mathrm{U} / \mathrm{mL})$ for $12 \mathrm{~h}$, followed by NBD-cholesterol $(1 \mu \mathrm{g} / \mathrm{mL})$ for additional $6 \mathrm{~h}$ in the absence or presence of apoAI $(10 \mu \mathrm{g} / \mathrm{mL})$ or HDL $(50 \mu \mathrm{g} / \mathrm{mL})$. The medium and cell lysates were collected for the measurement of fluorescence. The calculation of cholesterol efflux is defined as fluorescence in the medium relative to the total amount of fluorescence. Data are mean \pm SEM from 5 independent experiments. ${ }^{*} P<0.05$ versus vehicle-treated group, ${ }^{\#} P<0.05$ versus EPO-treated group.

$[4,8]$, which is in line with our current findings, confirming the interaction between EPOR and $\beta$ CR in BMSMs. In the adult, EPO is typically produced by the kidney, and EPOR is mainly expressed by cells in bone marrow; however, the level of EPOR in nonerythroid cells was much lower than that in erythroid cells [1-8]. Moreover, the binding affinity of the cytoprotective EPOR2- $\beta$ CR2 complex for EPO is significantly lower as compared to the affinity of erythropoietic EPOR2 complex $[7,8]$. The expressed pattern of EPOR2$\beta C R 2$ and its affinity with EPO in nonerythroid cells may explain the observation that the activation of EPOR2- $\beta$ CR2 by EPO required much higher concentrations of EPO compared to that of EPOR2 $[7,8]$.

In addition to the practice of EPO in the treatment of anemia and renal diseases $[2,3]$, emerging evidence suggests that EPO has other beneficial effects on nonerythroid tissues [4-8]. However, a major disadvantage in the use of $\mathrm{EPO}$ as a cytoprotective agent is its stimulated effect on erythropoiesis $[7,8]$, which may indirectly influence the therapeutic efficacy of EPO or increase the risk of cardiovascular 


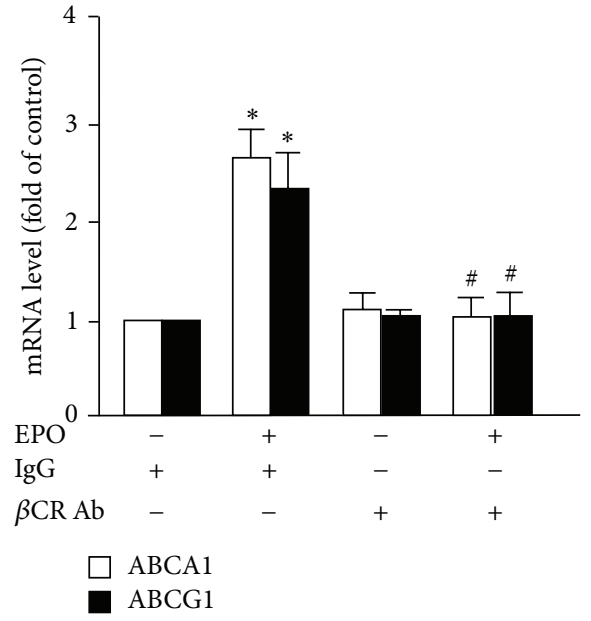

(a)

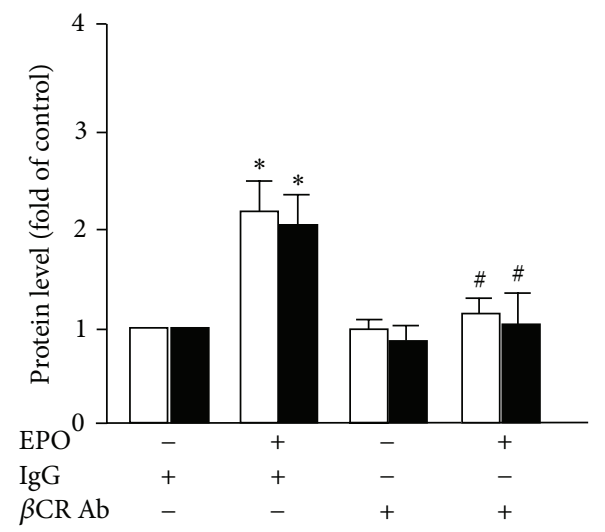

$\square$ ABCA1

- ABCG1

(c)

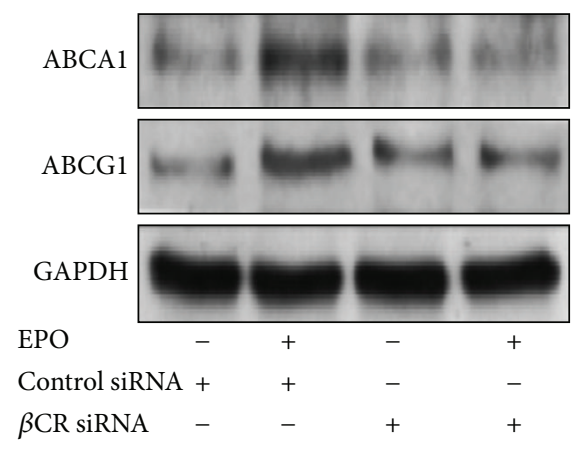

(e)

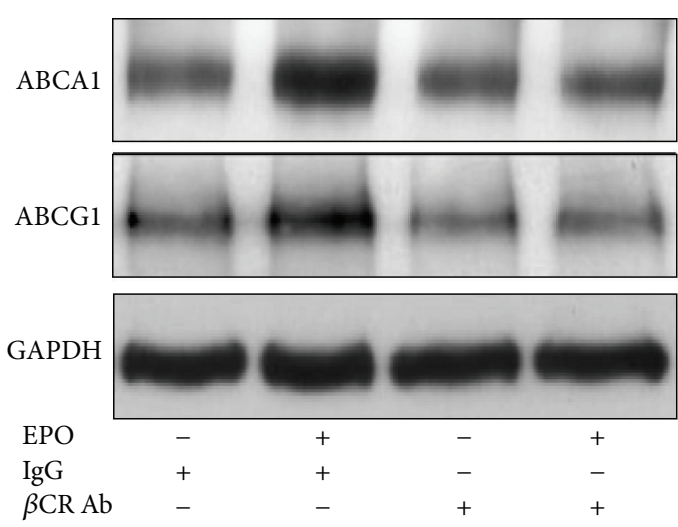

(b)

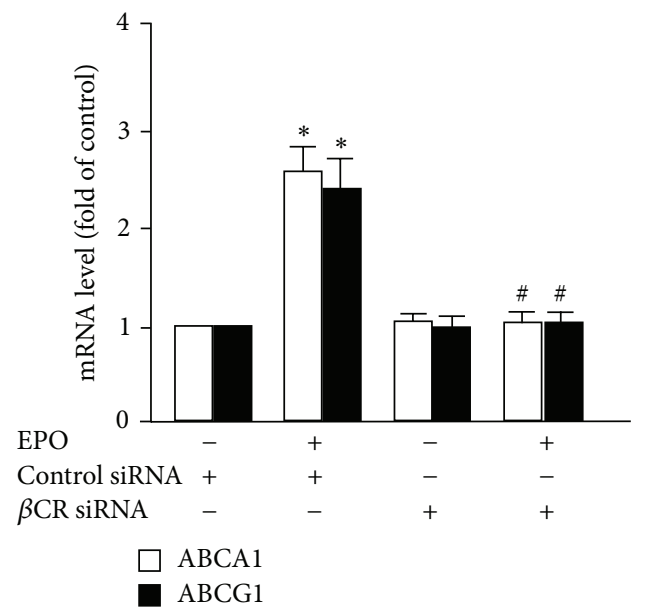

(d)

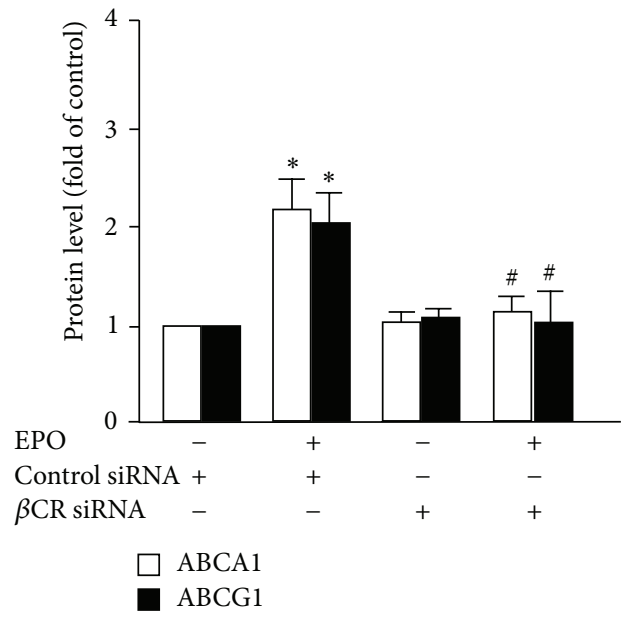

(f)

FIGURE 7: Blockage of $\beta C R$ activation ablates EPO-induced upregulation of ABCA1 and ABCG1 transporters in macrophages. Bone-marrowderived macrophages were pretreated with $\operatorname{IgG}(200 \mathrm{ng} / \mathrm{mL})$ or $\beta$ CR neutralizing $\mathrm{Ab}(200 \mathrm{ng} / \mathrm{mL})$ for $2 \mathrm{~h}$ (b) transfection with control siRNA $(50 \mathrm{nmole} / \mathrm{L})$ or $\beta$ CR siRNA $(50 \mathrm{nmole} / \mathrm{L})$ for $24 \mathrm{~h}$ and then treated with EPO $(5 \mathrm{U} / \mathrm{mL})$ for $12 \mathrm{~h}$ or $24 \mathrm{~h}$. Cell were lyzed and lyates subjected to RT-PCR and western blot analysis for mRNA or protein expression of ABCA1, ABCG1, and GAPDH. Data is mean \pm SEM from 5 independent experiments. ${ }^{*} P<0.05$ versus vehicle-treated group and ${ }^{\#} P<0.05$ versus EPO-treated group. 


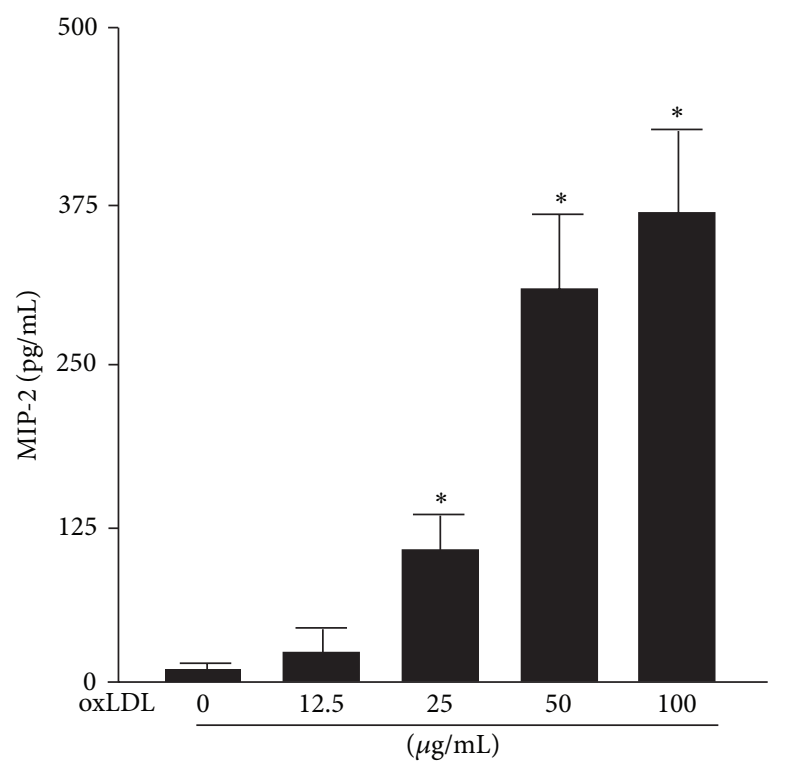

(a)

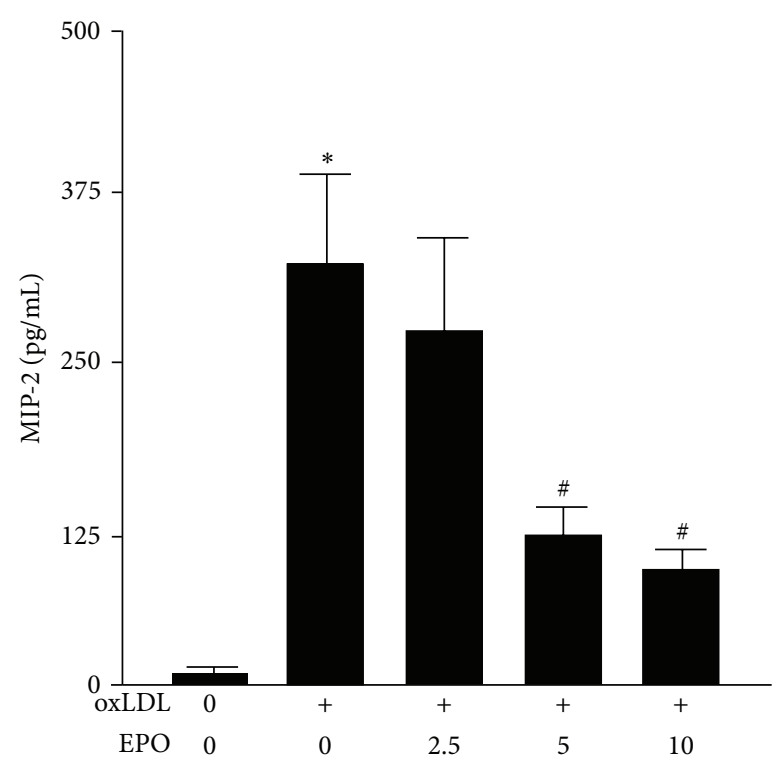

(b)

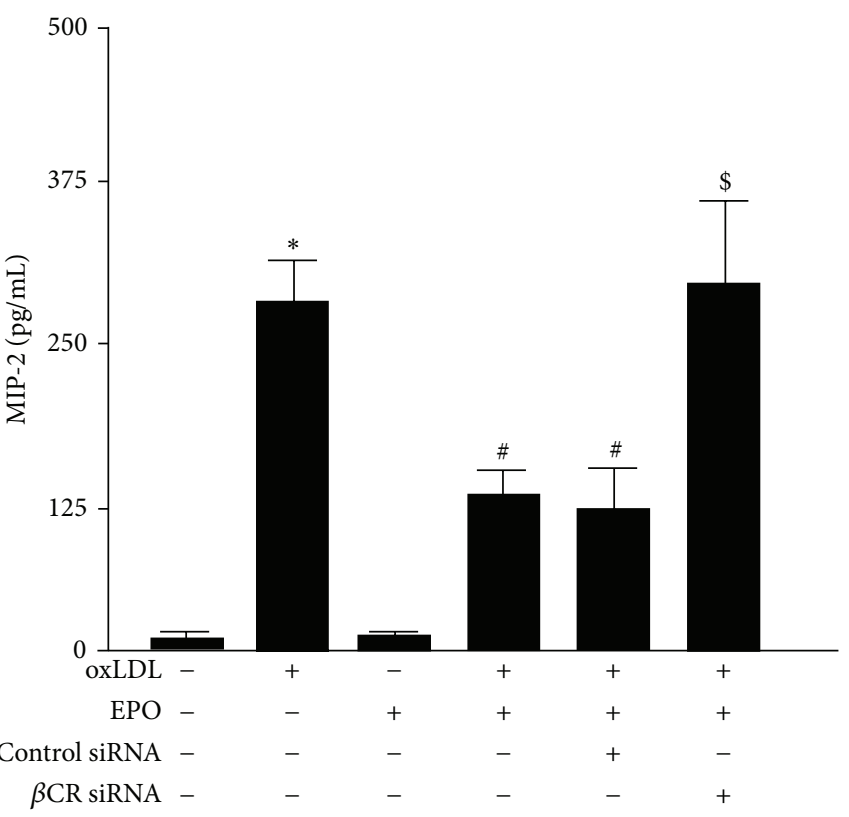

(d)

FIGURE 8: Inhibition of $\beta \mathrm{CR}$ activation prevents the protective effect of EPO against from the oxLDL-induced MIP-2 production in macrophages. (a) BMDMs were treated with indicated concentrations of oxLDL $(12.5,25,50$, and $100 \mu \mathrm{g} / \mathrm{mL}$ ) for $24 \mathrm{~h}$. (b) Cells were treated with oxLDL $(50 \mu \mathrm{g} / \mathrm{mL})$ in the absence or presence of indicated concentrations of EPO $(2.5,5$, and $10 \mathrm{U} / \mathrm{mL})$ for $24 \mathrm{~h}$. (c) Cells were pretreated with IgG $(200 \mathrm{ng} / \mathrm{mL})$ or $\beta$ CR neutralizing $\mathrm{Ab}(200 \mathrm{ng} / \mathrm{mL})$ for $2 \mathrm{~h}$ or $(\mathrm{d})$ transfection with control siRNA $(50 \mathrm{nmole} / \mathrm{L})$ or $\beta \mathrm{CR}$ siRNA $(50 \mathrm{nmole} / \mathrm{L})$ for $24 \mathrm{~h}$ and then treated with oxLDL $(50 \mu \mathrm{g} / \mathrm{mL})$ and EPO $(5 \mathrm{U} / \mathrm{mL})$ for an additional 24 h. Levels of MIP- 2 in cultured medium were analyzed by ELISA. Data are mean \pm SD from 5 independent experiments. ${ }^{*} P<0.05$ versus vehicle-treated group, ${ }^{\#} P<0.05$ versus oxLDL alone-treated group, and ${ }^{\$} P<0.05$ versus oxLDL-treated group with EPO-treatment.

adverse events [7, 8]. For instance, polycythemic transgenic mice overexpressing EPO have increased the whole blood viscosity and enhanced platelet activation [49], which may induce life threatening adverse effects such as thrombotic events on clinical application [7, 8, 50]. To avoid these offtarget events during the last decades, EPO derivatives have been developed that only activate the EPOR2- $\beta c R 2$ com- plex and do not stimulate erythropoiesis [51-54]. For instance, carbamylated EPO, a nonhematopoietic analogue of EPO, which can bind to EPOR2- $\beta$ CR2, is reported to provide comparable neuronal and myocardial cytoprotection with EPO in experimental animal models $[51,52]$. More recent, ARA290, a small synthetic peptide without erythropoietic properties, selectively binds to EPOR2- $\beta$ CR2 complex, and 
has been shown to confer renoprotection in the renal ischemia/reperfusion model [53, 54]. Mechanistically, EPO and its EPO derivatives afford several beneficial effects including anti-inflammation and antiapoptosis, as well as promotion of $\mathrm{NO}$ bioavailability by activating in a cascade of Janus kinase-2 (JAK2) signaling pathway or Akt signaling pathway $[7,8,53,54]$. Our previous studies showed that the effect of EPO on NO production of ECs is mediated through the activation $\beta \mathrm{CR} / \mathrm{JAK} 2 / \mathrm{Akt} / \mathrm{AMPK} / \mathrm{eNOS}$ signaling pathway $[17,55]$. In this study, we indeed observed that inhibition of JAK2 activation or Akt by pharmacological inhibitors abrogated the EPO-mediated suppression on the oxLDL-induced lipid accumulation in macrophage foam cells (data not shown). Nevertheless, whether carbamylated EPO and ARA290 afford the comparable protection as EPO, from the formation of foam cells and atherosclerosis, remains in need for further investigations.

\section{Conclusions}

In conclusion, this study demonstrates a unique function of $\beta \mathrm{CR}$ in EPO-mediated cytoprotection from oxLDL-induced deregulation of lipid metabolism and inflammatory response in macrophages. Our findings provide advanced information in EPO-conferred protection and suggest that $\beta \mathrm{CR}$ may have therapeutic value in treating atherosclerosis-related cardiovascular diseases.

\section{Conflict of Interests}

The authors declared that they have no conflict of interests.

\section{Acknowledgments}

This study was supported by Grants from the the National Science Council (99-2320-B-010-017-MY3, 101-2628-B-010001-MY2, 102-2628-B-010-001-MY3, and 101-2811-B-010039), VGHUST Joint Research Program, Tsou's Foundation (VGHUST 101-G7-5-3 and VGHUST 102-G7-5-2), ChengHsin General Hospital (101F195CY05 and 102F218C07), the Department of Health of Taipei City Government (10101-62029), and Ministry of Education, Aim for the Top University Plan, Taiwan. The authors thank the National Yang-Ming University-VGH Genome Research Center for technical support.

\section{References}

[1] F. Stohlman Jr., S. Ebbe, B. Morse, D. Howard, and J. Donovan, "Regulation of erythropoiesis. XX. Kinetics of red cell production," Annals of the New York Academy of Sciences, vol. 149, no. 1, pp. 156-172, 1968.

[2] J. V. Brugniaux, "Erythropoietin: friend and foe!," Acta Physiologica, vol. 212, no. 2, pp. 125-127, 2014.

[3] L. Wang, L. Di, and C. T. Noguchi, "Erythropoietin, a novel versatile player regulating energy metabolism beyond the erythroid system," International Journal of Biological Sciences, vol. 10, no. 8, pp. 921-939, 2014.
[4] D. M. Bailey, C. Lundby, R. M. G. Berg et al., "On the antioxidant properties of erythropoietin and its association with the oxidative-nitrosative stress response to hypoxia in humans," Acta Physiologica, vol. 212, no. 2, pp. 175-187, 2014.

[5] D. Burger, M. Lei, N. Geoghegan-Morphet, X. Lu, A. Xenocostas, and Q. Feng, "Erythropoietin protects cardiomyocytes from apoptosis via up-regulation of endothelial nitric oxide synthase," Cardiovascular Research, vol. 72, no. 1, pp. 51-59, 2006.

[6] K. Satoh, Y. Kagaya, M. Nakano et al., "Important role of endogenous erythropoietin system in recruitment of endothelial progenitor cells in hypoxia-induced pulmonary hypertension in mice," Circulation, vol. 113, no. 11, pp. 1442-1450, 2006.

[7] M. Choi, S. Y. Ko, I. Y. Lee et al., "Carbamylated erythropoietin promotes neurite outgrowth and neuronal spine formation in association with CBP/p300," Biochemical and Biophysical Research Communications, vol. 446, no. 1, pp. 79-84, 2014.

[8] K. Pawlak, D. Pawlak, and M. Mysliwiec, "Long-term erythropoietin therapy decreases CC-chemokine levels and intimamedia thickness in hemodialyzed patients," American Journal of Nephrology, vol. 26, no. 5, pp. 497-502, 2006.

[9] Z. Cai, D. J. Manalo, G. Wei et al., "Hearts from rodents exposed to intermittent hypoxia or erythropoietin are protected against ischemia-reperfusion injury," Circulation, vol. 108, no. 1, pp. 7985, 2003.

[10] D. Ribatti, M. Presta, A. Vacca et al., "Human erythropoietin induces a pro-angiogenic phenotype in cultured endothelial cells and stimulates neovascularization in vivo," Blood, vol. 93, no. 8, pp. 2627-2636, 1999.

[11] J. M. Al-Qahtani, B. A. Abdel-Wahab, and S. M. Abd El-Aziz, "Long-term moderate dose exogenous erythropoietin treatment protects from intermittent hypoxia-induced spatial learning deficits and hippocampal oxidative stress in young rats," Neurochemical Research, vol. 39, no. 1, pp. 161-171, 2014.

[12] K. C. Siamopoulos, C. Gouva, K. P. Katopodis et al., "Longterm treatment with EPO increases serum levels of high-density lipoprotein in patients with CKD," The American Journal of Kidney Diseases, vol. 48, no. 2, pp. 242-249, 2006.

[13] K.-Y. Lu, L.-C. Ching, K.-H. Su et al., "Erythropoietin suppresses the formation of macrophage foam cells: role of liver $\mathrm{X}$ receptor $\alpha$," Circulation, vol. 121, no. 16, pp. 1828-1837, 2010.

[14] A. I. Khan, S. M. Coldewey, N. S. A. Patel et al., "Erythropoietin attenuates cardiac dysfunction in experimental sepsis in mice via activation of the $\beta$-common receptor, Disease Models \& Mechanisms, vol. 6, no. 4, pp. 1021-1030, 2013.

[15] S. M. Coldewey, A. I. Khan, A. Kapoor et al., "Erythropoietin attenuates acute kidney dysfunction in murine experimental sepsis by activation of the $\beta$-common receptor," Kidney International, vol. 84, no. 3, pp. 482-490, 2013.

[16] L. Sautina, Y. Sautin, E. Beem et al., "Induction of nitric oxide by erythropoietin is mediated by the $\beta$ common receptor and requires interaction with VEGF receptor 2," Blood, vol. 115, no. 4, pp. 896-905, 2010.

[17] K.-H. Su, S.-K. Shyue, Y. R. Kou et al., “ $\beta$ common receptor integrates the erythropoietin signaling in activation of endothelial nitric oxide synthase," Journal of Cellular Physiology, vol. 226, no. 12, pp. 3330-3339, 2011.

[18] M. Brines, G. Grasso, F. Fiordaliso et al., "Erythropoietin mediates tissue protection through an erythropoietin and common $\beta$-subunit heteroreceptor," Proceedings of the National Academy of Sciences of the United States of America, vol. 101, no. 41, pp. 14907-14912, 2004. 
[19] J. Wei, L.-C. Ching, J.-F. Zhao et al., "Essential role of transient receptor potential vanilloid type 1 in evodiamine-mediated protection against atherosclerosis," Acta Physiologica, vol. 207, no. 2, pp. 299-307, 2013.

[20] C.-Y. Lin, T.-S. Lee, C.-C. Chen et al., "Endothelin-1 exacerbates lipid accumulation by increasing the protein degradation of the ATP-binding cassette transporter G1 in macrophages," Journal of Cellular Physiology, vol. 226, no. 8, pp. 2198-2205, 2011.

[21] J.-F. Zhao, L.-C. Ching, Y. R. Kou et al., "Activation of TRPV1 prevents OxLDL-induced lipid accumulation and TNF- $\alpha$ induced inflammation in macrophages: role of liver $\mathrm{X}$ receptor

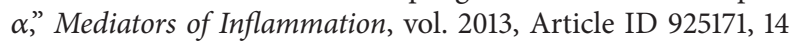
pages, 2013.

[22] J.-F. Zhao, S.-J. Jim Leu, S.-K. Shyue, K.-H. Su, J. Wei, and T.-S. Lee, "Novel effect of paeonol on the formation of foam cells: promotion of LXR $\alpha$-ABCA1 dependent cholesterol efflux in macrophages," American Journal of Chinese Medicine, vol. 41, no. 5, pp. 1079-1096, 2013.

[23] F. Zheng, S. Xing, Z. Gong et al., "Silence of NLRP3 suppresses atherosclerosis and stabilizes plaques in apolipoprotein Edeficient mice," Mediators of Inflammation, vol. 2014, Article ID 507208, 8 pages, 2014.

[24] A. Pirillo, G. D. Norata, and A. L. Catapano, "LOX-1, OxLDL, and atherosclerosis," Mediators of Inflammation, vol. 2013, Article ID 152786, 12 pages, 2013.

[25] P. Shashkin, B. Dragulev, and K. Ley, "Macrophage differentiation to foam cells," Current Pharmaceutical Design, vol. 11, no. 23, pp. 3061-3072, 2005.

[26] M. Viñals, I. Bermúdez, G. Llaverias et al., "Aspirin increases CD36, SR-BI, and ABCA1 expression in human THP-1 macrophages," Cardiovascular Research, vol. 66, no. 1, pp. 141-149, 2005.

[27] N. S. Sabeva, C. M. McPhaul, X. Li, T. J. Cory, D. J. Feola, and G. A. Graf, "Phytosterols differentially influence ABC transporter expression, cholesterol efflux and inflammatory cytokine secretion in macrophage foam cells," The Journal of Nutritional Biochemistry, vol. 22, no. 8, pp. 777-783, 2011.

[28] J.-F. Zhao, S.-K. Shyue, S.-J. Lin, J. Wei, and T.-S. Lee, "Excess nitric oxide impairs $\operatorname{LXR}(\alpha)$-ABCAl-dependent cholesterol efflux in macrophage foam cells," Journal of Cellular Physiology, vol. 229, no. 1, pp. 117-125, 2014.

[29] M. Z. Ashraf and N. Gupta, "Scavenger receptors: implications in atherothrombotic disorders," International Journal of Biochemistry and Cell Biology, vol. 43, no. 5, pp. 697-700, 2011.

[30] C.-Y. Tsou, C.-Y. Chen, J.-F. Zhao et al., "Activation of soluble guanylyl cyclase prevents foam cell formation and atherosclerosis," Acta Physiologica, vol. 210, no. 4, pp. 799-810, 2014.

[31] J.-F. Zhao, L.-C. Ching, Y.-C. Huang et al., "Molecular mechanism of curcumin on the suppression of cholesterol accumulation in macrophage foam cells and atherosclerosis," Molecular Nutrition and Food Research, vol. 56, no. 5, pp. 691-701, 2012.

[32] C.-Y. Chen, S.-K. Shyue, L.-C. Ching et al., "Wogonin promotes cholesterol efflux by increasing protein phosphatase 2B-dependent dephosphorylation at ATP-binding cassette transporter-A1 in macrophages," The Journal of Nutritional Biochemistry, vol. 22, no. 11, pp. 1015-1021, 2011.

[33] J.-Y. Tsai, K.-H. Su, S.-K. Shyue et al., "EGb761 ameliorates the formation of foam cells by regulating the expression of SR-A and ABCA1: role of haem oxygenase-1," Cardiovascular Research, vol. 88, no. 3, pp. 415-423, 2010.

[34] T.-S. Lee, C.-C. Pan, C.-C. Peng et al., "Anti-atherogenic effect of berberine on LXR $\alpha$-ABCA1-dependent cholesterol efflux in macrophages," Journal of Cellular Biochemistry, vol. 111, no. 1, pp. 104-110, 2010.

[35] T.-S. Lee, C.-Y. Lin, J.-Y. Tsai et al., "Resistin increases lipid accumulation by affecting class A scavenger receptor, CD36 and ATP-binding cassette transporter-A1 in macrophages," Life Sciences, vol. 84, no. 3-4, pp. 97-104, 2009.

[36] C.-Y. Chen, L.-C. Ching, Y.-J. Liao et al., "Deficiency of glycine $\mathrm{N}$-methyltransferase aggravates atherosclerosis in apolipoprotein E-null mice," Molecular Medicine, vol. 18, no. 5, pp. 744-752, 2012.

[37] L.-C. Cheng, K.-H. Su, Y. R. Kou et al., “ $\alpha$-Lipoic acid ameliorates foam cell formation via liver X receptor $\alpha$-dependent upregulation of ATP-binding cassette transporters A1 and G1," Free Radical Biology and Medicine, vol. 50, no. 1, pp. 47-54, 2011.

[38] X. Zhang, Q.-Y. Li, and B.-G. Xiao, "Anti-inflammatory effect of erythropoietin therapy on experimental autoimmune encephalomyelitis," International Journal of Neuroscience, vol. 122, no. 5, pp. 255-262, 2012.

[39] N. Ahmadiasl, S. Banaei, A. Alihemmati, B. Baradaran, and E. Azimian, "The anti-inflammatory effect of erythropoietin and melatonin on renal ischemia reperfusion injury in male rats," Advanced Pharmaceutical Bulletin, vol. 4, no. 1, pp. 49-54, 2014.

[40] N. Kertesz, J. Wu, T. H.-P. Chen, H. M. Sucov, and H. Wu, “The role of erythropoietin in regulating angiogenesis," Developmental Biology, vol. 276, no. 1, pp. 101-110, 2004.

[41] J. H. Holstein, M. Orth, C. Scheuer et al., "Erythropoietin stimulates bone formation, cell proliferation, and angiogenesis in a femoral segmental defect model in mice," Bone, vol. 49, no. 5, pp. 1037-1045, 2011.

[42] K. A. S. Vilarinho, P. P. M. de Oliveira, M. J. A. Saad et al., "Erythropoietin protects the systolic function of neonatal hearts against ischaemia/reperfusion injury," European Journal Cardio-Thoracic Surgery, vol. 43, no. 1, pp. 156-162, 2013.

[43] P. V. D. Meer, E. Lipsic, R. H. Henning et al., "Erythropoietin improves left ventricular function and coronary flow in an experimental model of ischemia-reperfusion injury," European Journal of Heart Failure, vol. 6, no. 7, pp. 853-859, 2004.

[44] H. Ehrenreich, K. Weissenborn, H. Prange et al., "Recombinant human erythropoietin in the treatment of acute ischemic stroke," Stroke, vol. 40, no. 12, pp. e647-e656, 2009.

[45] A. Phrommintikul, S. J. Haas, M. Elsik, and H. Krum, "Mortality and target haemoglobin concentrations in anaemic patients with chronic kidney disease treated with erythropoietin: a meta-analysis," The Lancet, vol. 369, no. 9559, pp. 381-388, 2007.

[46] V. Allegra, L. Martimbianco, and A. Vasile, "Lipid and apolipoprotein patterns during erythropoietin therapy: roles of erythropoietin, route of administration, and diet," Nephrology Dialysis Transplantation, vol. 12, no. 5, pp. 924-932, 1997.

[47] C. A. Pollock, R. Wyndham, P. V. Collett et al., "Effects of erythropoietin therapy on the lipid profile in end-stage renal failure," Kidney International, vol. 45, no. 3, pp. 897-902, 1994.

[48] M. Buemi, A. Allegra, F. Corica et al., "Does erythropoietin administration affect progression of atherosclerosis in Watanabe heritable hyperlipaemic rabbits?" Nephrology Dialysis Transplantation, vol. 13, no. 10, pp. 2706-2708, 1998.

[49] F. T. Ruschitzka, R. H. Wenger, T. Stallmach et al., "Nitric oxide prevents cardiovascular disease and determines survival in polyglobulic mice overexpressing erythropoietin," Proceedings of the National Academy of Sciences of the United States of America, vol. 97, no. 21, pp. 11609-11613, 2000. 
[50] C. Moreau, R. Lariviere, I. Kingma, J. H. Grose, and M. Lebel, "Chronic nitric oxide inhibition aggravates hypertension in erythropoietin-treated renal failure rats," Clinical and Experimental Hypertension, vol. 22, no. 7-8, pp. 663-674, 2000.

[51] M. Brines, N. S. A. Patel, P. Villa et al., "Nonerythropoietic, tissue-protective peptides derived from the tertiary structure of erythropoietin," Proceedings of the National Academy of Sciences of the United States of America, vol. 105, no. 31, pp. 10925-10930, 2008.

[52] F. Fiordaliso, S. Chimenti, L. Staszewsky et al., "A nonerythropoietic derivative of erythropoietin protects the myocardium from ischemia-reperfusion injury," Proceedings of the National Academy of Sciences of the United States of America, vol. 102, no. 6, pp. 2046-2051, 2005.

[53] W. G. van Rijt, G. J. Nieuwenhuijs-Moeke, H. van Goor et al., "ARA290, a non-erythropoietic EPO derivative, attenuates renal ischemia/reperfusion injury," Journal of Translational Medicine, vol. 11, no. 1, article 9, 8 pages, 2013.

[54] W. G. Van Rijt, G. J. Nieuwenhuijs-Moeke, H. Van Goor, P. J. Ottens, R. J. Ploeg, and H. G. D. Leuvenink, "Renoprotective capacities of non-erythropoietic EPO derivative, ARA290, following renal ischemia/reperfusion injury," Journal of Translational Medicine, vol. 11, no. 1, article 286, 2013.

[55] K.-H. Su, Y.-B. Yu, H.-H. Hou et al., "AMP-activated protein kinase mediates erythropoietin-induced activation of endothelial nitric oxide synthase," Journal of Cellular Physiology, vol. 227, no. 8, pp. 3053-3062, 2012. 


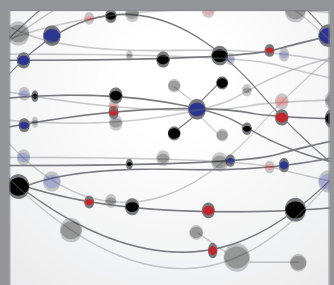

The Scientific World Journal
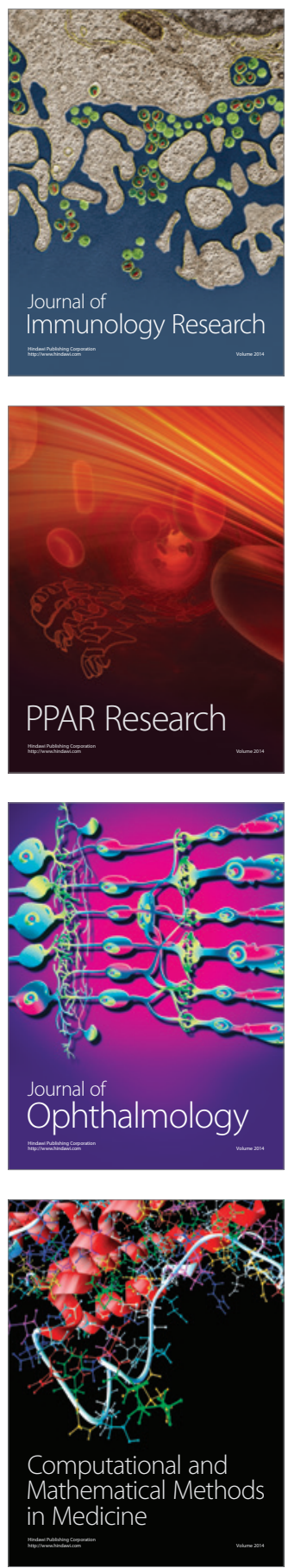

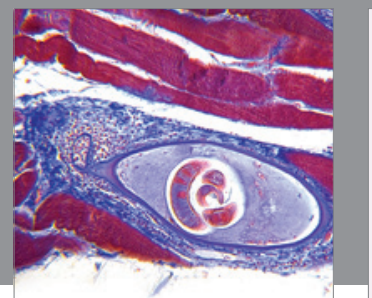

Gastroenterology

Research and Practice
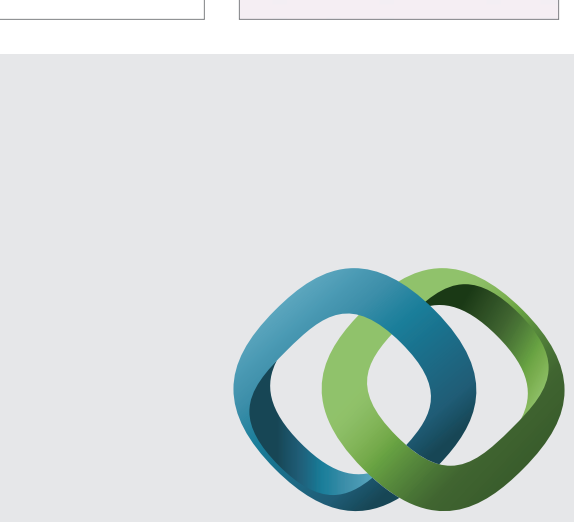

\section{Hindawi}

Submit your manuscripts at

http://www.hindawi.com
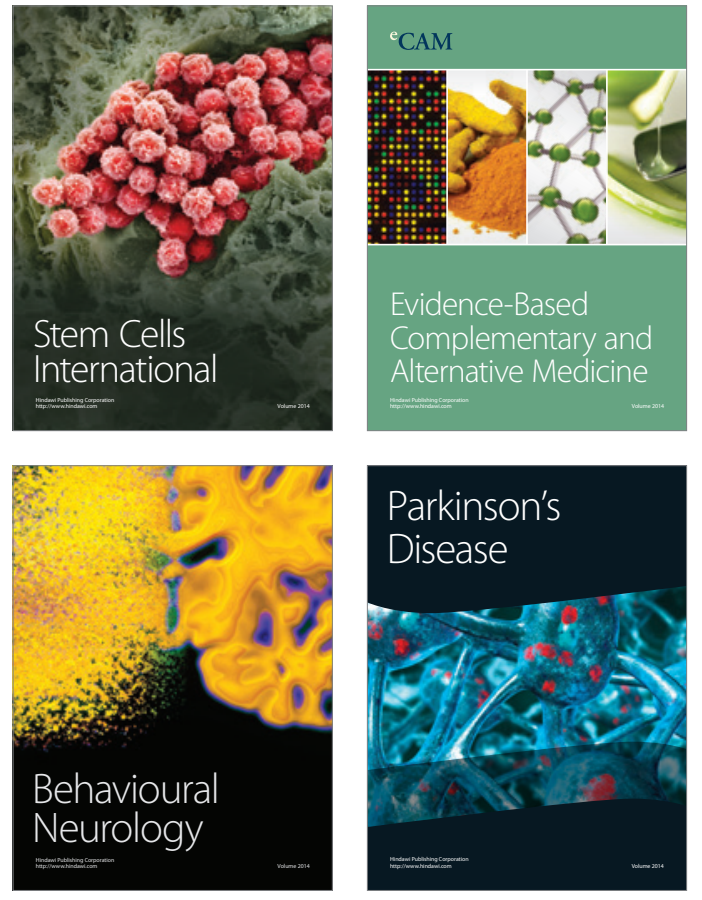
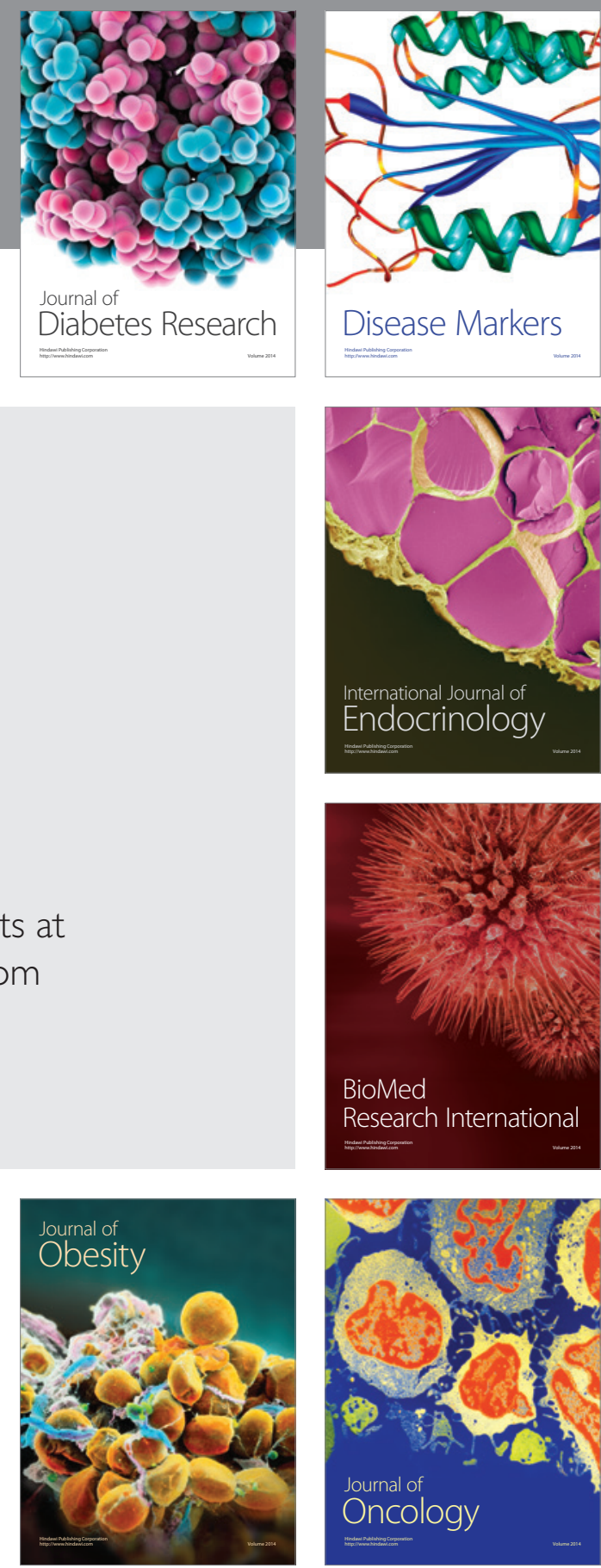

Disease Markers
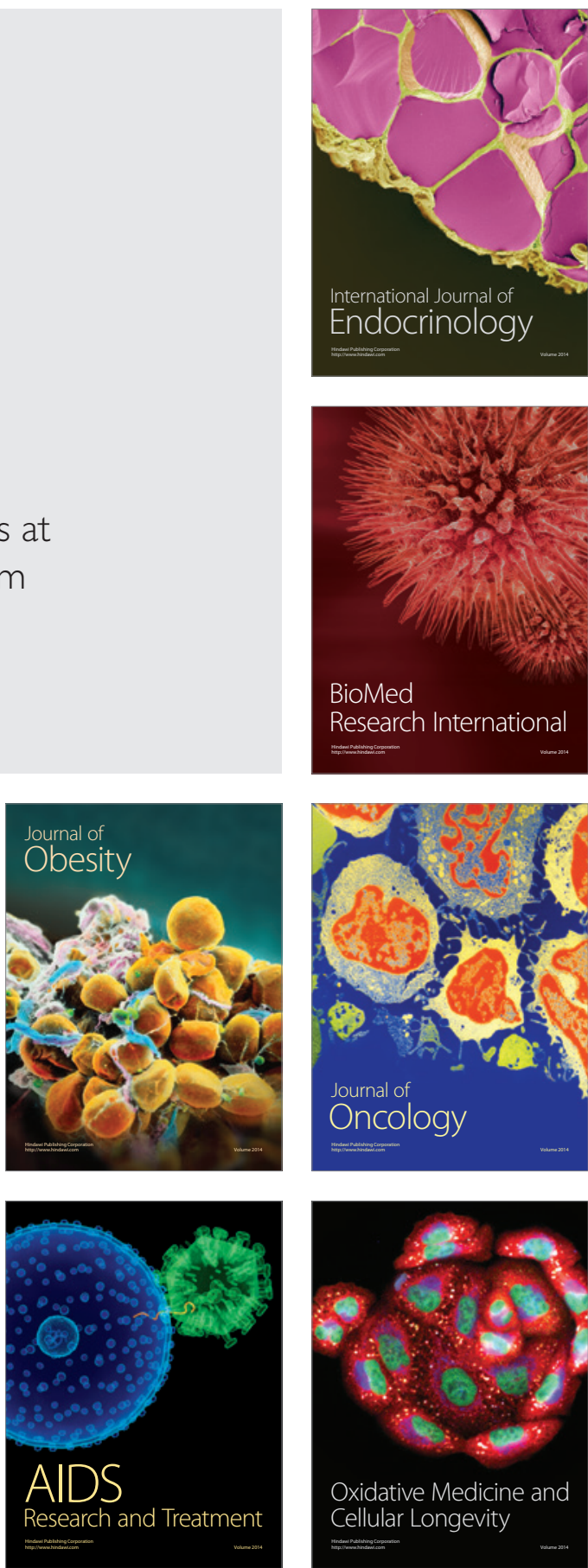